\title{
EDITORIAL
}

\section{What will it take to put talking about death on our agenda?}

Striking gains in longevity and medical science have increased the need for conversations about end-of-life care preferences. Whereas, previously most deaths were primarily due to acute infectious illnesses affecting people of all ages, in the new millennium the majority of deaths now occur in older people following years of living with chronic illnesses. Technological advances have extended life beyond what was once considered possible, helping us to become in many respects a death defying society. Consequently, too few people plan for this inevitable life stage or their subsequent death. Whilst some people may have attended to various legal and financial matters, and perhaps even made funeral arrangements, few will have considered, discussed or documented their wishes around: organ donation; where they would like to die; and which life sustaining treatment they consider appropriate and in what circumstances (Dying Matters, 2013).

The challenges of discussing end-of-life care preferences in part reflect society's reluctance to acknowledge death. This has prompted the development of various community led initiatives, such as the UK based 'Dying Matters' Coalition and the 'Ground Swell' Project in Australia which aim to promote greater public awareness of issues related to dying, death and bereavement. These community action groups are working to make conversations about 'living and dying well' the norm by encouraging people to consider: registering to become an organ donor; making an effort to call someone at the end of their life or someone recently bereaved; asking someone they love about 'the five things they would like to do before they die'; helping them to tick these items off their 'bucket list'; and/or asking them to list the five things they want to be remembered by' (Dying Matters, 2013).

Australia has some of the lowest deceased organ donation rates in the developed world (Halls, 2012). Although a donor's age and medical history are taken into consideration, there is no age limit on the donation of some organs and tissues. Despite this more expansive donor eligibility criteria, various patient, provider and system factors in Australia influence consent rates for deceased organ donations, such as: decedents having had prior conversations with families about their donation wishes; cultural and religious differences impacting on emergency department clinicians, confidence to initiate organ and tissue donation related conversations (Weiland, Marck, Jelinek, Neate, \& Hickey, 2013); and Australia's current legislation requiring organ donors to 'opt-in'(Halls, 2012). In some European countries people are required to consciously 'opt-out', which increased deceased organ donor rates (Halls, 2012).

Advance care planning conversations are important for everyone, but essential for people with a confirmed progressive life limiting illness, and insurance should they lack capacity in the future to participate in shared-decisionmaking. Involving the family and other members of the health care team in advance care planning conversations is essential and ought to be initiated at the time of diagnosis of a progressive life limiting illness (e.g. advanced dementia, heart failure, cancer, motor-neuron disease) and revisited following hospitalisations and/or when the person has declining functional status (Brunnhuber, Nash, Meier, Weissman, \& Woodcock, 2008).

Despite widespread endorsement from patients, families and clinicians for advance care planning conversations, few people go on to complete an advance care directive. A lack of time and medico-legal uncertainty has limited their uptake in Australia and the difficulties of transmitting advance care planning preferences across care settings has limited adherence. However, the Australian Government's recent announcement of two major initiatives will do much to address these challenges and promote the uptake of advance care planning nationally.

The first initiative will enable Advance Care Directives to be stored in the Personally Controlled Electronic Health Record (Australian and Government, 2013) ensuring that clinicians in all care settings have access to patients' histories and their treatment preferences in specific clinical circumstances. The success of this initiative will largely be dependent upon all health professionals having the capabilities to initiate advance care planning conversations 
to identify patients' preferences and to assist patient's to develop and modify their on-line advance care plans accordingly.

The second initiative brings together seven organisations with expert knowledge and experience in palliative and aged care to create an innovative 24-7, 1800 number Advisory Service. This service will support those working in aged and primary care to improve the delivery of palliative care and advance care planning for older Australians receiving aged care services (Palliative Care Australia, 2013). It is anticipated that this initiative will help to ensure that the 60,000 older Australians who die each year in aged care are not transferred unnecessarily to acute care because of insufficient planning or because of difficulty accessing timely medical care and/or because they have unmet palliative care needs.

Thinking about and initiating end-of-life care wishes and organ donation preference conversations with our patients, families and friends is challenging. However, there are resources to help us initiate and shape these conversations using simple, clear but sensitive language (Clayton et al., 2007). In our personal lives, regardless of our age and health state, we all ought to also be having these conversations with those we love. Simply asking a relative or friend who they would like you to contact if they became very seriously ill is potentially one of the easiest ways of opening up this subject (Dying Matters, 2013). If they have a serious progressive life-limiting illness it conveys that you know they may not recover and are willing to talk about it, whilst giving them the space to decide whether or not to respond. So be courageous and start these conversations today.

\section{References}

Australian Government. (2013). Advance care plans to be included on e-health records. Retrieved 22 September 2013, from http://www.health.gov.au/internet/ministers/publishing.nsf/ Content/mr-yr13-tp-tp037.htm

Brunnhuber, K., Nash, S., Meier, D. E., Weissman, D. E., \& Woodcock, J. (2008, Spring). Putting evidence into practice: palliative care. In British Medical Journal Group. United Health Foundation.

Clayton, J. M., Hancock, K. M., Butow, P. N., Tattersall, M. H., Currow, D. C., \& Adler, J. D. (2007). Clinical practice guidelines for communicating prognosis and end-of-life issues with adults in the advanced stages of a life-limiting illness, and their caregivers. Medical Journal of Australia, 187(8), 478.

Dying Matters. (2013). Our resources. Retrieved 22 September 2013, from http: //dyingmatters.org/overview/resources

Halls, A. (2012). Potential law reform for Australia's organ donation system. Journal of Law and Medicine, 20(2), 306-319.

Palliative Care Australia. (2013). New advisory service will improve palliative and end of life care for older Australians. Retrieved 22 September 2013, from http://www. palliativecare.org.au/Portals/46/media/2013/3.pdf

Weiland, T. J., Marck, C. H., Jelinek, G. A., Neate, S. L., \& Hickey, B. B. (2013). Attitudes of Australian emergency department clinicians toward organ and tissue donation: An analysis of cultural and religious influences. Progress In Transplantation, 23(3), 278-289. http://dx.doi.org/10.7182/pit2013511

Jane Phillips

The University of Notre Dame, Australia, School of Nursing, and The Cunningham Centre for Palliative Care Sydney, Australia 